\title{
The Reactions Between Cellulose Nitrate and Heterocyclic Compounds
}

Svetlana M. Romanova, Dinara I. Pavlova, Almira M. Madyakina and Marsel V. Khuzeev* Kazan National Research Technological University 68 Karl Marks Str., Kazan', 420015, Russia

Received 17.04.2015, received in revised form 09.06.2015, accepted 08.08.2015

The reactions of cellulose nitrate with imidazole and 2-methylimidazole are researched. As a result of reactions solid polymeric and monomeric soluble products are obtained. The elemental composition of this substances is determined and empirical formula of the elementary unit is calculated. On the basis of quantum-chemical calculations perfomed using the Gaussian 09 and physic chemical methods of analysis structure of the products have been established and the most probable directions of the reaction are offered.

Keywords: cellulose nitrate, imidazole, 2-methylimidazole, nucleophilic substitution, chemical modification, electron density distribution.

\section{Реакции нитратов целлюлозы}

с гетероциклическими соединениями

С.М. Романова, Д.И. Павлова, А.М. Мадякина, М.В. Хузеев Казанский национальный исследовательский технологический университет Россия, 420015, Казань, ул. Карла Маркса, 68

Исследованы реакции нитратов целлюлозы с имидазолом и 2-метилимидазолом. В результате экспериментов получены твердые полимерные и мономерные водорастворимые продукты, для

C) Siberian Federal University. All rights reserved

* Corresponding author E-mail address: romsvetlana80@mail.ru 
которых определен элементный состав и рассчитаны эмпирические формулы элементарного звена. На основании квантово-химического расчёта, выполненного с помощьюю программы Gaussian 09, и физико-химических методов анализа установлены структуры продуктов и предложены наиболее вероятные пути протекания реакиий.

Ключевые слова: нитрат целлюлозы, имидазол, 2-метилимидазол, нуклеофильное замещение, химическая модификация, распределение электронной плотности.

\section{Введение}

В связи с необходимостью снятия с вооружения и вывода из боевого состава Вооруженных сил РФ морально и технически устаревших образцов военной техники и боеприпасов возникла проблема их промышленной утилизации. Перед военно-промышленным комплексом страны была поставлена задача организации мощных производств по переработке устаревших порохов на основе нитратов целлюлозы (НЦ), которая определилась в первую очередь масштабами подлежащих ликвидации запасов, экономической нецелесообразностью их безвозвратных потерь, требованиями экологической безопасности [1].

В настоящее время интенсивно ведутся работы по утилизации нитратцеллюлозных порохов, извлеченных из боеприпасов, путем физико-химической и химической модификации [2-5]. Их перерабатывают в промышленные взрывчатые вещества для народно-хозяйственного назначения, новые виды пороха для военных целей, лаки, клеи, эмали, линолеум, влагостойкие и антикоррозийные покрытия и др.

Новым перспективным направлением применения смешанных эфиров целлюлозы является производство современной наукоемкой продукции: детекторов ионизирующих излучений, биологических индикаторов, полупроницаемых мембран, селективных сорбентов. Это обстоятельство существенно стимулирует проведение исследований по разработке методов модификации полимера для получения материалов с заданными свойствами.

Одним из способов химического модифицирования нитратов целлюлозы признано замещение их функциональных групп иными группами по реакциям нуклеофильного и электрофильного замещения, что позволяет целенаправленно изменять комплекс их свойств: повышать устойчивость к химическим реагентам, расширять область температурной переработки и др.

Целью данной работы стало исследование химических реакций НЦ с имидазолом и 2-метилимидазолом и выявление направлений взаимодействия на основании различных методов анализа.

\section{Экспериментальная часть}

\section{Физико-химические методы анализа}

ИК-спектры записывали на спектрометре Фурье «Avatar-360» с математическим обеспечением «OMNIC» в интервале частот 400-4000 $\mathrm{cm}^{-1}$. Точность определения частот поглощения $\pm 3 \mathrm{~cm}^{-1}$.

Спектры ЯMP ${ }^{~} \mathrm{H}$ записывали на спектрометре Bruker MSL-400, ${ }_{\mathrm{H}}=400$ МГц (растворитель дейтерированный диметилсульфоксид, внутренний стандарт $\left.\left(\mathrm{CH}_{3}\right)_{4} \mathrm{Si}\right)$.

$$
-337-
$$


Микроскопическое исследование оптически анизотропных элементов, фазовых элементов и фазовых переходов изучали на поляризационном микроскопе МИН-8.

Характеристическую вязкость определяли на вискозиметре ВПЖ-3 в ацетоне.

Молекулярные массы полимеров измеряли методом ГПХ на хроматографе «ViscotecGPCmaxVE-2001» (растворитель - тетрагидрофуран).

\section{Характеристика исходного нитрата целлюлозы}

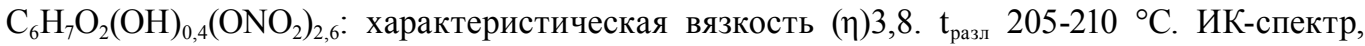
$v, \mathrm{~cm}^{-1}:$ 700-690, 750, 840, 1280, 1380, 1430, 1650-1670 (-ONO $)$; 1070 (С-О-С); 1170-1120 (глюкопи-

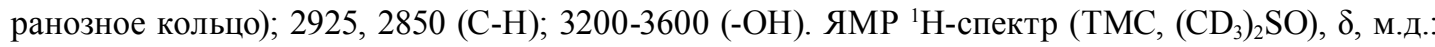
$5,75\left({ }^{3} \mathrm{H}\right), 5,15\left({ }^{2,4} \mathrm{H}\right), 4,8\left({ }^{6} \mathrm{H}\right), 4,1\left({ }^{1,5} \mathrm{H}\right), 3,67-3,83(\mathrm{OH})$. Найдено, \%: С 24,97; Н 2,60; N 13,05. Вычислено, \%: С 25,81; Н 2,65; N 13,05.

\section{Общая методика проведения эксперимента}

Реакция нитрата целлюлозы с имидазолом.

Получение полимеров. В круглодонную колбу на 250 мл приливали 70 мл спиртоэфирной смеси (соотношение этилового спирта к диэтиловому эфиру 50:50) и добавляли 2 г НЦ, перемешивали до полного растворения полимера. К полученному раствору добавляли навеску имидазола, исходя из расчета 1 моль на каждую нитратную группу полимера. Реакционную массу перемешивали и выдерживали $1,3,5,7,9$ и 11 ч при температуре $20^{\circ} \mathrm{C}$.

Реакция нитрата целлюлозы с 2-метилимидазолом.

Получение полимеров. В круглодонную колбу на 250 мл приливали 70 мл 96\%-ного этанола и добавляли 2 г НЦ. К полученной смеси добавляли навеску 2-метилимидазола, исходя из расчета 1 моль на каждую нитратную группу полимера. Реакционную массу перемешивали и выдерживали $1,3,5$ и 7 ч при температурах 60 и $78{ }^{\circ} \mathrm{C}$.

После синтеза полученную реакционную массу высаживали в дистиллированную воду. Далее полученную суспензию, состоящую из продуктов реакции, отфильтровывали на воронке Шотта № 4. Твердый осадок неоднократно промывали дистиллированной водой для удаления растворителя и побочных продуктов реакции и высушивали сначала на воздухе, а далее в вакуум-эксикаторе над хлористым кальцием до постоянной массы.

\section{Получение водорастворимых продуктов}

Легколетучие растворители, которые содержались в фильтрате, оставшемся после отделения твердого осадка от реакционной массы, испарялись на открытом воздухе. По окончании процесса извлекали коричневый маслянистый остаток, который промывали изопропиловым спиртом до кристаллов коричневого оттенка и высушивали.

\section{Характеристики продуктов взаимодействия НЦ с имидазолом}

1) $\mathrm{C}_{6} \mathrm{H}_{7} \mathrm{O}_{2}(\mathrm{OH})_{1,05}\left(\mathrm{ONO}_{2}\right)_{1,61}\left(\mathrm{C}_{3} \mathrm{H}_{3} \mathrm{~N}_{2}\right)_{0,34}\left(\mathrm{t}_{\text {реакц. }}=20^{\circ} \mathrm{C}, \tau=3\right.$ ч): выход 77,1\%. теристическая вязкость (ๆ) 2,35. ИК-спектр, $v$, cм$^{-1}$ : 700-690, 750, 840, 1280, 1380, 1430, 1650-1670 $\left(-\mathrm{ONO}_{2}\right) ; 1070$ (С-О-С); 1170-1120 (глюкопиранозное кольцо); 1530-1550 (-C=N, -C=C); 2925, 2850 (C-H); 3440-3400 (N-H); 3200-3600 (-OH). ЯMP ${ }^{1} \mathrm{H}-$ спектр (TMC, $\left.\left(\mathrm{CD}_{3}\right)_{2} \mathrm{SO}\right), \delta$, м.д.: 5,75 ( $\left.{ }^{3} \mathrm{H}\right), 5,15$ 
$(2,4 \mathrm{H}), 4,8\left({ }^{6} \mathrm{H}\right), 4,1\left({ }^{1,5} \mathrm{H}\right), 3,67-3,83(-\mathrm{OH}) ; 7,30$ (протоны гетероатомного кольца имидазола). Найдено, \%: С 33,42; Н 4,09; N 12,84. Вычислено, \%: С 33,50; Н 3,61; N 12,75.

2) $\mathrm{C}_{6} \mathrm{H}_{7} \mathrm{O}_{2}(\mathrm{OH})_{1,39}\left(\mathrm{ONO}_{2}\right)_{1,17}\left(\mathrm{C}_{3} \mathrm{H}_{3} \mathrm{~N}_{2}\right)_{0,44} \quad\left(\mathrm{t}_{\text {реакц }}=20 \quad{ }^{\circ} \mathrm{C}, \quad \tau=7 \quad\right.$ ч): $\quad$ выход $65,5 \quad \% . \quad \mathrm{t}_{\text {разл }}$ 210-215 ${ }^{\circ}$ С. Характеристическая вязкость (ๆ) 1,61. ИК-спектр, $v$, см $^{-1}:$ 700-690, 750, 840, 1280, 1380 , 1430, 1650-1670 (-ONO 2$) ; 1070$ (С-О-С); 1170-1120 (глюкопиранозное кольцо); 1530-1550 (-C=N, -C=C); 2925, 2850 (C-H); 3440-3400 (N-H); 3200-3600 (-OH). ЯMP ${ }^{1} \mathrm{H}$-спектр (TMC, $\left.\left(\mathrm{CD}_{3}\right)_{2} \mathrm{SO}\right), \delta$, м.д.: 5,75 $\left({ }^{3} \mathrm{H}\right), 5,15\left({ }^{2,4} \mathrm{H}\right), 4,8\left({ }^{6} \mathrm{H}\right), 4,1\left({ }^{1,5} \mathrm{H}\right), 3,67-3,83(-\mathrm{OH}) ; 7,30$ (протоны гетероатомного кольца имидазола). Найдено, \%: С 36,93; Н 4,19; N 12,38. Вычислено, \%: С 37,12; Н 4,10; N 12,13.

3) $\mathrm{C}_{6} \mathrm{H}_{7} \mathrm{O}_{2}(\mathrm{OH})_{1,28}\left(\mathrm{ONO}_{2}\right)_{0,82}\left(\mathrm{C}_{3} \mathrm{H}_{3} \mathrm{~N}_{2}\right)_{0,90}\left(\mathrm{t}_{\text {реакц. }}=20^{\circ} \mathrm{C}, \tau=11\right.$ ч): выход 57,2 \%. $\mathrm{t}_{\text {разл }} 210-215^{\circ} \mathrm{C}$. Характеристическая вязкость ( ) 1,23. ИК-спектр, $v, \mathrm{~cm}^{-1}:$ 700-690, 750, 840, 1280, 1380, 1430, 1650-1670 $\left(-\mathrm{ONO}_{2}\right) ; 1070$ (C-O-C); 1170-1120 (глюкопиранозное кольцо); 1530-1550 (-C=N, -C=C); 2925, 2850 (C-H); 3440-3400 (N-H); 3200-3600 (-OH). ЯМР ' ${ }^{1}$-спектр (TMC, $\left.\left(\mathrm{CD}_{3}\right)_{2} \mathrm{SO}\right), \delta$, м.д.: 5,75 ( $\left.{ }^{3} \mathrm{H}\right), 5,15$ $\left({ }^{2,4} \mathrm{H}\right), 4,8\left({ }^{6} \mathrm{H}\right), 4,1\left({ }^{1,5} \mathrm{H}\right), 3,67-3,83(-\mathrm{OH}) ; 7,30$ (протоны гетероатомного кольца имидазола). Найдено, \%: С 42,48; Н 5,35; N 14,82. Вычислено, \%: С 42,50; Н 5,20; N 14,93.

\section{Характеристики продуктов взаимодействия НЦ с 2-метилимидазолом}

1) $\mathrm{C}_{6} \mathrm{H}_{7} \mathrm{O}_{2}(\mathrm{OH})_{1,08}\left(\mathrm{ONO}_{2}\right)_{0,52}\left(\mathrm{C}_{4} \mathrm{H}_{5} \mathrm{~N}_{2}\right)_{1,40}\left(\mathrm{t}_{\text {реакц. }}=60{ }^{\circ} \mathrm{C}, \tau=3\right.$ ч): выход 71,3\%. $\mathrm{t}_{\text {разл }} 195-210{ }^{\circ} \mathrm{C}$. Характеристическая вязкость (ๆ) 1,95. ИК-спектр, $v, \mathrm{~cm}^{-1}: 700-690,750,840,1280,1380,1430,1650$ $1670\left(-\mathrm{ONO}_{2}\right) ; 1070$ (С-О-С); 1170-1120 (глюкопиранозное кольцо); 1530-1550 (-C=N, -C=C); 2925, 2850 (C-H); 3440-3400 (N-H); 3200-3600 (-OH). ЯМР ${ }^{1} \mathrm{H}$-спектр (ТMC, $\left.\left(\mathrm{CD}_{3}\right)_{2} \mathrm{SO}\right), \delta$, м.д.: 1,25 $\left(\mathrm{H}-\mathrm{CH}_{2}-\mathrm{C}\right) ; 5,75\left({ }^{3} \mathrm{H}\right), 5,15\left({ }^{2,4} \mathrm{H}\right), 4,8\left({ }^{6} \mathrm{H}\right), 4,1\left({ }^{1,5} \mathrm{H}\right), 3,67-3,83(-\mathrm{OH}) ; 7,30$ (протоны гетероатомного кольца 2-метилимидазола). Найдено, \%: С 51,01; Н 4,88; N 16,21. Вычислено, \%: С 50,78; Н 5,50; N 16,86 .

2) $\mathrm{C}_{6} \mathrm{H}_{7} \mathrm{O}_{2}(\mathrm{OH})_{1,45}\left(\mathrm{ONO}_{2}\right)_{0,25}\left(\mathrm{C}_{4} \mathrm{H}_{5} \mathrm{~N}_{2}\right)_{1,30}\left(\mathrm{t}_{\text {реакц }}=60{ }^{\circ} \mathrm{C}, \tau=7\right.$ часов): выход $37,8 \%$. $\mathrm{t}_{\text {разл }} 190-210{ }^{\circ} \mathrm{C}$. Характеристическая вязкость (ๆ) 1,36. ИК-спектр, $v \mathrm{~cm}^{-1}: 700-690,750,840,1280,1380,1430$, 1650-1670 (- $\left.\mathrm{ONO}_{2}\right) ; 1070$ (С-О-С); 1170-1120 (глюкопиранозное кольцо); 1660-1480 (имидазольное

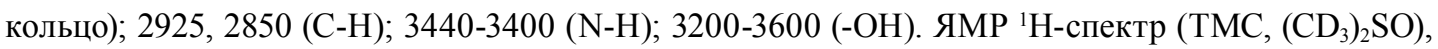
$\delta$, м.д.: 1,25 $\left(\mathrm{H}_{-} \mathrm{CH}_{2}-\mathrm{C}\right) ; 5,75\left({ }^{3} \mathrm{H}\right), 5,15\left({ }^{2,4} \mathrm{H}\right), 4,8\left({ }^{6} \mathrm{H}\right), 4,1\left({ }^{1,5} \mathrm{H}\right), 3,67-3,83(-\mathrm{OH}) ; 7,30$ (протоны гетероатомного кольца 2-метилимидазола). Найдено, \%: С 51,80; Н 5,45; N 15,62. Вычислено, \%: C 52,40; H 5,83; N 15,56.

3) $\mathrm{C}_{6} \mathrm{H}_{7} \mathrm{O}_{2}(\mathrm{OH})_{1,62}\left(\mathrm{ONO}_{2}\right)_{0,33}\left(\mathrm{C}_{4} \mathrm{H}_{5} \mathrm{~N}_{2}\right)_{1,05}\left(\mathrm{t}_{\text {реакц. }}=80{ }^{\circ} \mathrm{C}, \tau=3\right.$ ч): выход 67,3 \%. $\mathrm{t}_{\text {разл }} 190-215{ }^{\circ} \mathrm{C}$. Ха-

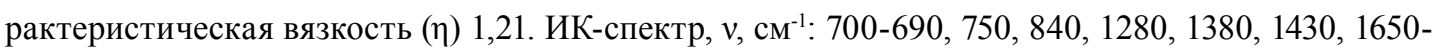
1670 (-ОNO $\left.)_{2}\right) ; 070$ (С-О-С); 1170-1120 (глюкопиранозное кольцо); 1530-1550 (-C=N, -C=C); 2925, 2850 (C-H); 3440-3400 (N-H); 3200-3600 (-OH). ЯМР ${ }^{1} \mathrm{H}$-спектр (TMC, $\left.\left(\mathrm{CD}_{3}\right)_{2} \mathrm{SO}\right), \delta$, м.д.: 1,25 $\left(\mathrm{H}-\mathrm{CH}_{2}-\mathrm{C}\right) ; 5,75\left({ }^{3} \mathrm{H}\right), 5,15\left({ }^{2,4} \mathrm{H}\right), 4,8\left({ }^{6} \mathrm{H}\right), 4,1\left({ }^{1,5} \mathrm{H}\right), 3,67-3,83(-\mathrm{OH}) ; 7,30$ (протоны гетероатомного кольца 2-метилимидазола). Найдено, \%: С 49,62; Н 4,64; N 14,13. Вычислено, \%: С 50,15; Н 5,68; N 13,94.

4) $\mathrm{C}_{6} \mathrm{H}_{7} \mathrm{O}_{2}(\mathrm{OH})_{1,8}\left(\mathrm{ONO}_{2}\right)_{0,1}\left(\mathrm{C}_{4} \mathrm{H}_{5} \mathrm{~N}_{2}\right)_{1,10}\left(\mathrm{t}_{\text {реакц. }}=80{ }^{\circ} \mathrm{C}, \tau=7\right.$ ч): выход $34,2 \%$. $\mathrm{t}_{\text {разл }}$ 195-215 ${ }^{\circ} \mathrm{C}$. Ха-

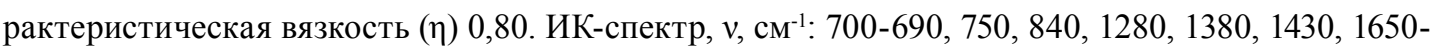
1670 (-ОNO 2 ); 1070 (С-О-С); 1170-1120 (глюкопиранозное кольцо); 1530-1550 (-C=N, -C=C); 2925, 2850 (C-H); 3440-3400 (N-H); 3200-3600 (-OH). ЯМР ${ }^{1} \mathrm{H}$ спектр (TMC, $\left.\left(\mathrm{CD}_{3}\right)_{2} \mathrm{SO}\right), \delta$, м.д.: 1,25 $\left(\mathrm{H}-\mathrm{CH}_{2}-\mathrm{C}\right) ; 5,75\left({ }^{3} \mathrm{H}\right), 5,15\left({ }^{2,4} \mathrm{H}\right), 4,8\left({ }^{6} \mathrm{H}\right), 4,1\left({ }^{1,5} \mathrm{H}\right), 3,67-3,83(-\mathrm{OH}) ; 7,30$ (протоны гетероатомного 
кольца 2-метилимидазола). Найдено, \%: С 51,87; Н 5,63; N 13,85. Вычислено, \%: С 52,68; Н 6,04; N 13,60.

\section{Характеристика полученного}

водорастворимого продукта реакиии НЦ с имидазолом

$\mathrm{C}_{6} \mathrm{H}_{7} \mathrm{O}_{2}(\mathrm{OH})_{1,23}\left(\mathrm{ONO}_{2}\right)_{0,95}\left(\mathrm{C}_{3} \mathrm{H}_{3} \mathrm{~N}_{2}\right)_{0,82} \quad\left(\mathrm{t}_{\text {реакц. }}=20 \quad{ }^{\circ} \mathrm{C}, \quad \tau=11 \quad\right.$ ч): $\quad$ выход $\quad 18,2 \quad \% . \quad \mathrm{t}_{\text {разл }}$

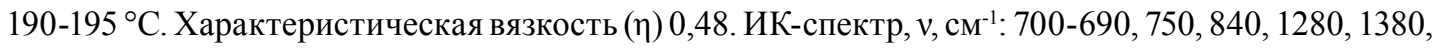
1430, 1650-1670 (-ONO $)$; 1070 (C-O-C); 1170-1120 (глюкопиранозное кольцо); 1530-1550 (-C=N,

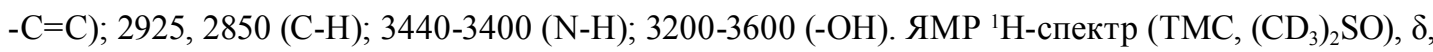
м.Д.: 5,75 $\left({ }^{3} \mathrm{H}\right), 5,15\left({ }^{2,4} \mathrm{H}\right), 4,8\left({ }^{6} \mathrm{H}\right), 4,1\left({ }^{1,5} \mathrm{H}\right), 3,67-3,83(-\mathrm{OH}) ; 7,30$ (протоны гетероатомного кольца имидазола). Найдено, \%: С 40,59; Н 5,03; N 14,62. Вычислено, \%: С 41,04; Н 4,98; N 14,66.

\section{Характеристика полученного}

водорастворимого продукта реакиии НЦ с 2-метилимидазолом

$\mathrm{C}_{6} \mathrm{H}_{7} \mathrm{O}_{2}(\mathrm{OH})_{1,65}\left(\mathrm{ONO}_{2}\right)_{0,45}\left(\mathrm{C}_{4} \mathrm{H}_{5} \mathrm{~N}_{2}\right)_{0,90} \quad\left(\mathrm{t}_{\text {реакц. }}=80 \quad{ }^{\circ} \mathrm{C}, \quad \tau=7 \quad\right.$ ч): $\quad$ выход $\quad 23,8 \quad \% . \quad \mathrm{t}_{\text {разл }}$ 190-195 ${ }^{\circ} \mathrm{C}$. Характеристическая вязкость (ๆ) 0,38. ИК-спектр, $v$, см $^{-1}: 700-690,750,840,1280$, 1380, 1430, 1650-1670 (-ONO 2$) ; 1070$ (С-О-С); 1170-1120 (глюкопиранозное кольцо); 1530-1550

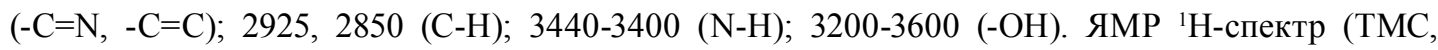
$\left.\left(\mathrm{CD}_{3}\right)_{2} \mathrm{SO}\right), \delta$, м.д.: $1,25\left(\mathrm{H}-\mathrm{CH}_{2}-\mathrm{C}\right) ; 5,75\left({ }^{3} \mathrm{H}\right), 5,15\left({ }^{2,4} \mathrm{H}\right), 4,8\left({ }^{6} \mathrm{H}\right), 4,1\left({ }^{1,5} \mathrm{H}\right), 3,67-3,83(-\mathrm{OH}) ; 7,30$ (протоны гетероатомного кольца 2-метилимидазола). Найдено, \%: С 47,61; Н 5,44; N 13,09. Вычислено, \%: С 48,03; Н 5,48; N 13,13.

\section{Обсуждение результатов}

Особенности химического строения макромолекул нитрата целлюлозы позволяют предполагать возможность химических превращений по различным реакционным центрам его элементарного звена: реакции по собственно нитратным группам, реакции по имеющимся свободным гидроксилам и реакции по гликозидным связям, всегда приводящие к деструкции полимерной цепи. Обзор научной и патентной литературы, касающейся этого вопроса, свидетельствует о том, что обычно при действии на нитраты целлюлозы химических реагентов различного характера, а также света и тепла наблюдаются в той или иной степени одновременно все три типа реакций, причем реакционная способность каждого из центров находится в прямой зависимости от соседнего окружения в элементарном звене, изменяющемся в процессе.

Для установления наиболее вероятных направлений взаимодействия нитратов целлюлозы с гетероциклическими соединениями были проведены квантово-химические расчеты для трех элементарных звеньев 2,6-динитрата целлюлозы. С этой целью использовалась программа Gaussian 09. Расчеты зарядов по Малликену выполнены с применением полуэмпирического метода квантовой химии АМ1. Структурная формула 2,6-динитрата целлюлозы с распределением зарядов на атомах представлена на рис. 1.

Электрофильные и нуклеофильные свойства молекулы определяются по знаку НВМО (значение энергии нижней вакантной орбитали). Если значение энергии НВМО отрицательное, то реагент лучше проявляет электрофильные свойства, а если положительное, то нуклеофильные 


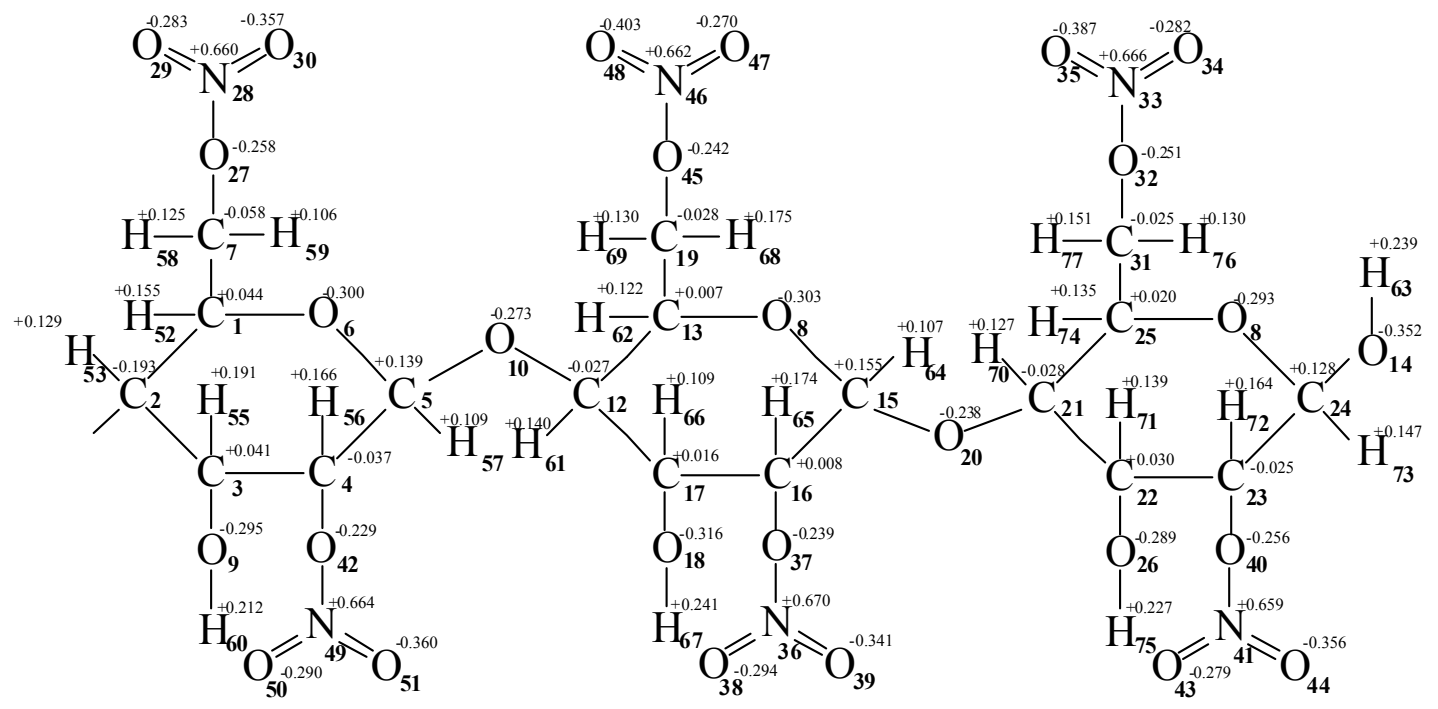

Рис. 1. Распределение зарядов на атомах 2,6-динитрата целлюлозы

свойства. Если же абсолютное значение энергии НВМО стремится к нулю, то данный реагент можно отнести как к нуклеофилу, так и к электрофилу. Для НЦ это значение -0,7763 эВ. Максимально отрицательные заряды на атоме кислорода в молекуле НЦ свидетельствуют о наиболее вероятном направлении прохождения электрофильной атаки, максимальные положительные заряды на атомах углерода и азота, соответственно, нуклеофильной атаки.

Как показали расчеты (рис. 1), в первую очередь атаке электрофилом подвергается углеродный атом (2) положений $\mathrm{C}_{(1)}$ и $\mathrm{C}_{(4)}$ глюкопиранозного кольца, приводящей к деполимеризации цепи макромолекулы НЦ, затем (7), (19), (31) углероды положений $\mathrm{C}_{(6)}$ с разрывом связи С-О. И только в последнюю очередь подвергаются атаке углероды положений $\mathrm{C}_{(2)}$ (углеродный атом (4)) также с разрывом связи С-О. Распределение зарядов оказывается подобным в порядке чередования через звено.

Наибольшим положительным зарядом в НЦ обладают атомы азота нитратных групп, следовательно, они будут в первую очередь подвергаться атаке нуклеофилом. Таким образом, в результате взаимодействия НЦ с веществами нуклеофильного характера согласно квантовохимическим расчетам наиболее вероятна атака нуклеофилом после атомов азота углеродов (5), (15), (24) в положениях $\mathrm{C}_{(1)}$ и $\mathrm{C}_{(4)}$, приводящая к деполимеризации макромолекул НЦ. Затем атаке нуклеофилом должны подвергаться углеродные атомы (1), (3), (17) и после (22), (25), соответствующие углеродным атомам $\mathrm{C}_{(3)}$ и $\mathrm{C}_{(5)}$, приводящие к замещению гидроксильных групп и раскрытию глюкопиранозного цикла соответственно. После этого происходит замещение нитратных групп у $\mathrm{C}_{(2)}$ (углеродный атом (16)).

Анализ зарядов на атомах не противоречит результатам, полученным ранее авторами [6, 7], с той лишь разницей, что в динитратах целлюлозы в случае нуклеофильной атаки в первую очередь после атаки положений $\mathrm{C}_{(1)}$ и $\mathrm{C}_{(4)}$, приводящих к деполимеризации, происходит замещение гидроксильных групп у $\mathrm{C}_{(3)}$, и только потом нитратных у $\mathrm{C}_{(2)}$, тогда как у тринитратов целлюлозы, описанных В.П. Пановым и Ю.А. Ждановым, после деполимеризации замещаются 
нитратные группы $\mathrm{C}_{(3)}$ и $\mathrm{C}_{(2)}$. Следует учитывать, что полимер представляет собой разнозвенную макромолекулу, состоящую из элементарных звеньев с различным содержанием нитратных и гидроксильных групп.

Большинство известных к настоящему времени химических взаимодействий нитратных групп азотнокислых эфиров целлюлозы можно условно разделить на реакции гетеролиза сложноэфирной связи, в результате чего регенерируется исходная гидроксильная группа либо образуются ангидро- или окисленные формы,на реакции нуклеофильного и электрофильного замещения нитратных групп, обусловленные сильной поляризацией имеющихся эфирных связей, с появлением новой эфирной связи, дезокси- и других производных, а также реакции термолиза, в ходе которых происходит разрыв пиранозного цикла и образование низкомолекулярных соединений.

На основании элементного анализа рассчитаны эмпирические формулы элементарных звеньев полученных продуктов (см. экспериментальную часть). Структуру соединений дока-

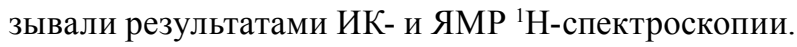

В ИК-спектрах конечных продуктов помимо полос поглощения, характерных для колеба-

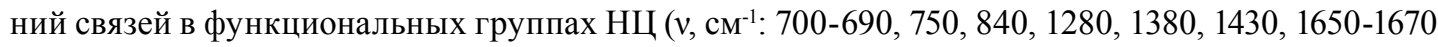
$\left(-\mathrm{ONO}_{2},-\mathrm{CH}_{2}-\mathrm{ONO}_{2}\right) ; 1070$ (C-O-C); 1170-1120 (глюкопиранозное кольцо)), наблюдаются полосы поглощения, характеризующие валентные и деформационные колебания связей функциональ-

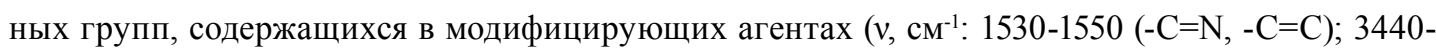
$3400(\mathrm{~N}-\mathrm{H}))$.

На спектрах ЯМР ${ }^{1}$ Н продуктов реакций различимы следующие сигналы (м. д.): 5,75 ( $\left.{ }^{3} \mathrm{H}\right)$, $5,15\left({ }^{2,4} \mathrm{H}\right), 4,8\left({ }^{6} \mathrm{H}\right), 4,1\left({ }^{1,5} \mathrm{H}\right)$, соответствующие протонам глюкопиранозного кольца; 7,30, отнесенный к протонам гетероатомного кольца имидазольного фрагмента. Помимо данных сигналов на спектрах продуктов реакции НЦ с 2-метилимидазолом появился сигнал 1,25 м.д., отнесенный к метильной группировке модифицирующего агента.

Об изменении молекулярной массы полимеров судили по изменению характеристической вязкости ацетоновых растворов продуктов реакции относительно раствора исходного НЦ $(3,8)$. Вязкость растворов продуктов в 1,5-3,5 раза ниже вязкости исходного полимера, что свидетельствует о частичной деструкции цепи макромолекул полимера, которая обусловлена разрывом $\beta$-гликозидных связей. С увеличением времени выдержки реакции вязкость растворов синтезированных полимеров уменьшается.

Для определения молекулярно-массовых характеристик исходного НЦ и полученных полимерных продуктов использовали метод гельпроникающей хроматографии. Анализ данных, приведенных в табл. 1, показывает, что реакции сопровождаются интенсивной деполимеризацией. Об этом свидетельствует уменьшение значений $\bar{M}_{n}$ и $\bar{M}_{\omega}$. Средневесовая молекулярная масса НЦ 128281 (стирольный эквивалент) существенно превышает значения средневесовой молекулярной массы синтезированных образцов.

На фоне протекания деполимеризационных процессов происходит повышение однородности молекулярно-массового состава, о чем свидетельствует уменьшение значения коэффициента полидисперсности.

На основании результатов физико-химических методов исследования и квантовохимического расчета предложены схема вероятных путей протекания реакции НЦ с данными 
Таблица 1. Молекулярно-массовые характеристики (в полистирольном эквиваленте) исходного НЦ и полимеров, полученных на его основе

\begin{tabular}{|l|c|c|c|c|}
\hline \multicolumn{1}{|c|}{ Соединение } & $\bar{M}_{n}$, Да & $\bar{M}_{\omega}$, Да & $\bar{M}_{z}$, Да & $\bar{M}_{\omega} / \bar{M}_{n}$ \\
\hline $\mathrm{C}_{6} \mathrm{H}_{7} \mathrm{O}_{2}(\mathrm{OH})_{0,46}\left(\mathrm{ONO}_{2}\right)_{2,54}$ & 15725 & 128281 & 1030000 & 8,16 \\
\hline $\begin{array}{l}\mathrm{C}_{6} \mathrm{H}_{7} \mathrm{O}_{2}(\mathrm{OH})_{1,28}\left(\mathrm{ONO}_{2}\right)_{0,82}\left(\mathrm{C}_{3} \mathrm{H}_{3} \mathrm{~N}_{2}\right)_{0,90} \\
\left(\mathrm{t}_{\text {peaкц. }}=20{ }^{\circ} \mathrm{C}, \tau=11 \text { часов }\right)\end{array}$ & 9629 & 26360 & 107538 & 2,81 \\
\hline $\begin{array}{l}\mathrm{C}_{6} \mathrm{H}_{7} \mathrm{O}_{2}(\mathrm{OH})_{1,8}\left(\mathrm{ONO}_{2}\right)_{0,1}\left(\mathrm{C}_{4} \mathrm{H}_{5} \mathrm{~N}_{2}\right)_{1,10} \\
\left(\mathrm{t}_{\text {peакц. }}=80{ }^{\circ} \mathrm{C}, \tau=7 \text { ч) }\right.\end{array}$ & 8931 & 24600 & 93432 & 2,78 \\
\hline
\end{tabular}

соединениями и структуры элементарных звеньев конечных продуктов замещения (рис. 2). Следует иметь в виду, что все процессы протекают одновременно.

Максимальной степени замещения на фрагменты имидазола удалось добиться при времени реакции 11 ч. Полученный продукт имеет эмпирическую формулу элементарного звена $\mathrm{C}_{6} \mathrm{H}_{7} \mathrm{O}_{2}(\mathrm{OH})_{1,28}\left(\mathrm{ONO}_{2}\right)_{0,82}\left(\mathrm{C}_{3} \mathrm{H}_{3} \mathrm{~N}_{2}\right)_{0,90}$. Дальнейшее увеличение времени выдержки приводило к сильной деструкции полимера, что затрудняло его выделение из реакционной смеси. В случае реакции с 2-метилимидазолом максимальное содержание гетероциклических фрагментов в продукте получено при $60{ }^{\circ} \mathrm{C}$ и трехчасовой выдержке. Формула элементарного звена данного полимера $\mathrm{C}_{6} \mathrm{H}_{7} \mathrm{O}_{2}(\mathrm{OH})_{1,08}\left(\mathrm{ONO}_{2}\right)_{0,52}\left(\mathrm{C}_{4} \mathrm{H}_{5} \mathrm{~N}_{2}\right)_{1,40}$. Большей степени замещения удалось добиться модификацией НЦ 2-метилимидазолом. Метильная группа, действуя как электроноотталкивающая, увеличивает электронную плотность у атома азота и тем самым усиливает основные свойства молекулы, что способствует протеканию нуклеофильного замещения.

\section{Выводы}

Представленные в работе экспериментальные данные свидетельствуют о том, что между высокоазотным НЦ и имидазолом в гомогенной среде спиртоэфирной смеси при $20^{\circ} \mathrm{C}$ и 2 -метилимидазолом в гетерогенной среде этанола при нагревании до $60-78{ }^{\circ} \mathrm{C}$ происходит химическое взаимодействие. Оно характеризуется рядом процессов: замещением функциональных групп НЦ на фрагмент гетероцикла, частичным гидролизом нитратных групп, разрывом $\beta$ гликозидных связей с присоединением по концам полимерной цепи в положения $\mathrm{C}_{1}$ и $\mathrm{C}_{4}$ имидазольных колец, а также частичной деполимеризацией полимера. Полученные в результате этих процессов полимерные продукты содержат меньшее число нитратных групп в элементарных звеньях, обладают меньшей молекулярной массой и имеют отличную от исходного НЦ структуру.

Продукты модификации НЦ имидазолом и его производными являются новыми целлюлозными материалами, которые могут в дальнейшем стать сырьем для производства различных товаров. 


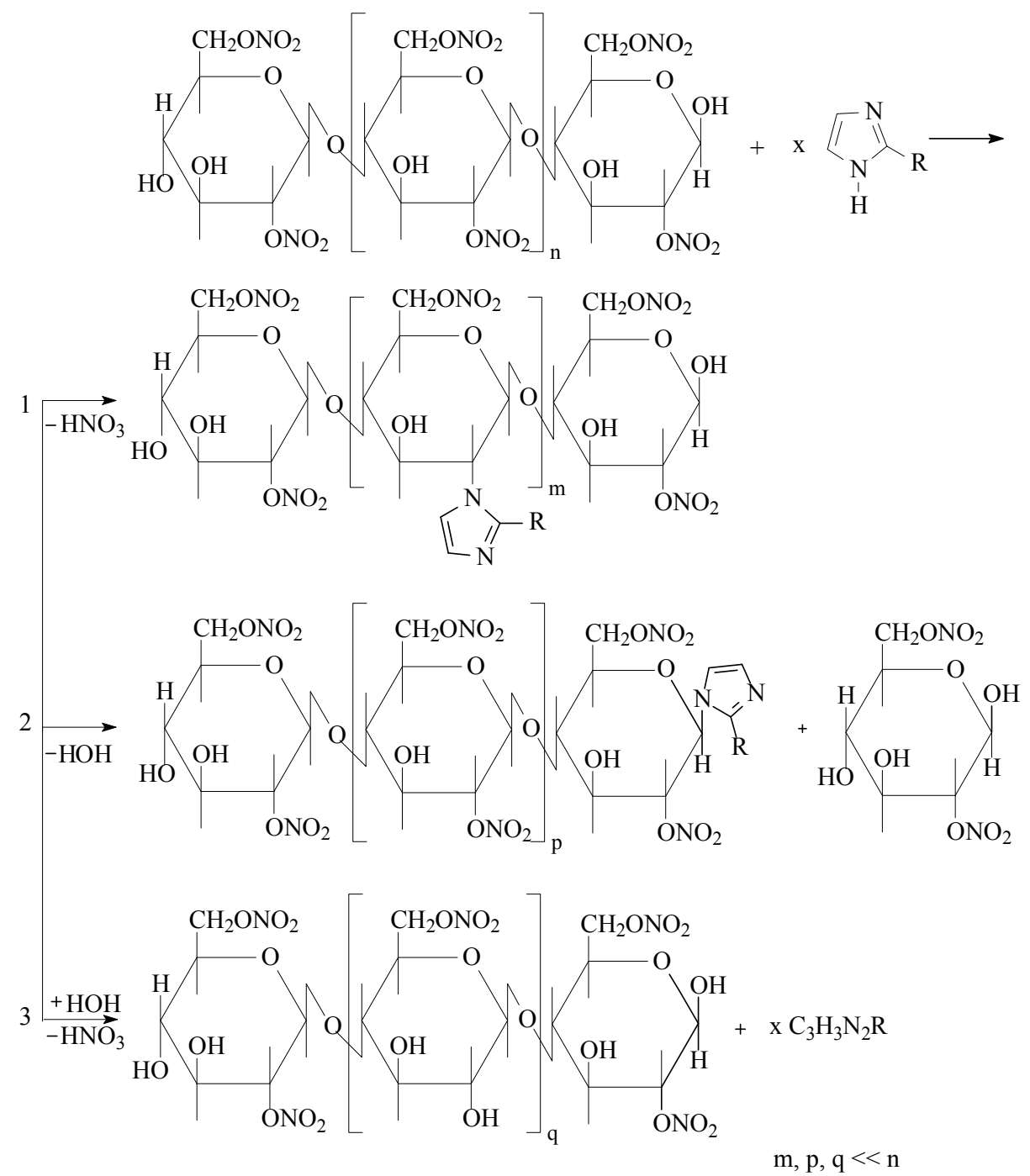

Рис. 2. Общая схема химического взаимодействия НЦ с имидазолом ( $\mathrm{R}=\mathrm{H}-)$ и 2-метилимидазолом $\left(\mathrm{R}=\mathrm{CH}_{3}-\right)$ : 1) нуклеофильное замещение нитратных групп на фрагмент $\left.-\mathrm{C}_{3} \mathrm{H}_{2} \mathrm{~N}_{2} \mathrm{R} ; 2\right)$ разрыв $\beta-$ гликозидной связи с присоединением радикала по концу полимерной цепи и деполимеризация цепи макромолекул полимера; 3) гидролиз нитратных групп 


\section{Список литературы}

1. Колмаков В.К. О целесообразности переработки метательных зарядов боеприпасов, запрещенных к боевому применению // Известия ТулГУ. Технические науки. Проблемы специального машиностроения 2011. Вып. 2. С. 294-297. [Kolmakov V.K. Aboutthe feasibilityofprocessingpropellantsofammunitionprohibitedforcombatuse. Izvestiya of Tula State University. Technical sciences. Problems of special mechanical engineering 2011. Vol. 2, P. 294297. (In Russ)]

2. Сарыбаева Р.И, Щелохова Л.С. Химия азотнокислых эфиров целлюлозы. Фрунзе: Илим, 1985. 164 c. [Sarybaeva R.I, Schelohova L.S. Chemistry of nitrate ethers of cellulose. Frunze: Ilim, 1985. 164 p. (In Russ)]

3. Мойсак И.Е. Химия и технология нитроцеллюлозы. М.: Обронгиз, 1941. 271 с. [Moysak I.E. Chemistry and technology of nitrocellulose. Moscow: Obrongiz, 1941. 271 p. (InRuss)]

4. Романова С.М., Фатыхова Л.А., Сабирова Д.И. Поиск альтернативных путей утилизации устаревших боеприпасов на основе нитратов целлюлозы // Вестник КТУ. 2012. Т. 15. № 14. C. 74-78. [Romanova S.M., Fatihova L.A., Sabirova D.I. Search for alternative ways of disposing of obsolete munitions based on cellulose nitrate. Vestnik of KTU. 2012. Vol. 15. № 14. P. 74-78. (In Russ)]

5. Романова С.М., Фатыхова Л.А., Сабирова Д.И. Утилизация устаревших боеприпасов на основе нитратов целлюлозы путем химической модификации. Вестник КТУ. 2013. Т.16. №4. C.129-131. [Romanova S.M., Fatihova L.A., Sabirova D.I. Disposal of obsolete munitions based on cellulose nitrate by chemical modification. Vestnik of KTU. 2013. Vol. 16. № 4. P. 129-131. (In Russ)]

6. Панов В.П., Жбанков Р.Г., Евдаков Н.В. Конформационный анализ тринитрата целлюлозы // Высокомолекулярные соединения. 1973. Т. А. 15. № 7. С. 1468-1477. [Panov V.P., Zhbankov R.G., Evdakov N.V. Conformational analysis of cellulose trinitrate. Macromolecular compounds 1973. Vol. A. 15. № 7. P. 1468-1477. (In Russ)]

7. Zhdanow Yu. A., Minkin V.Z., Ostroumov Y.A Conformational preferences of threenitrate cellulose // Carbohyd. Res. 1968. V. 7. P. 156-160. 